Tropical Journal of Pharmaceutical Research June 2018; 17 (6): 1073-1080

ISSN: $1596-5996$ (print); 1596-9827 (electronic)

(C) Pharmacotherapy Group, Faculty of Pharmacy, University of Benin, Benin City, 300001 Nigeria.

\title{
Analysis of Coscinium fenestratum Colebr stem extract and effect of the extract on mean arterial blood pressure, heart rate and force of contraction in rats
}

\author{
Wei Zhang ${ }^{1}$, Zhe $\mathrm{Li}^{1}$, Hang Meng ${ }^{1}$, Sophia Ogechi Ekeuku${ }^{2}$, Patrick Nwabueze \\ Okechukwu ${ }^{2 *}$ \\ ${ }^{1}$ Shaanxi Provincial People's Hospital, No. 256, Youyi West Road, Xian Shaanxi Province, China, ${ }^{2}$ Department of \\ Biotechnology, Faculty of Applied Sciences, UCSI University No. 1, Jalan Menara Gading, UCSI Heights, (Taman Connaught) \\ Cheras 56000, Kuala Lumpur, Malaysia
}

*For correspondence: Email: patrickn@ucsiuniversity.edu.my; 908408290@qq.com

Sent for review: 3 October 2017

Revised accepted: 14 May 2018

\begin{abstract}
Purpose: To evaluate the effect of Coscinium fenestratum (CF) crude extract on hypertension in animal models.

Methods: Dichloromethane (DCM), ethyl acetate (EA), and butanol (BuOH) extracts were obtained by fractionation from the crude methanol extract. The dried extracts were then administered to SpragueDawley $(250-300 \mathrm{mg})$ rats $(n=20)$ and frogs $(n=20)$ of either sex. CF effect on mean arterial blood pressure (MABP), heart rate (HR) and force of contraction (FOC) were assessed with the aid of Biopac Lab Pro Software. Atenolol (5 ug/ml) and acetylcholine (5 ug/ml) were used as controls. High performance liquid chromatography (HPLC) analysis and phytochemical studies were carried out on the extract.

Results: The methanol extract (M - E) reduced MABP by $45.60 \%$, HR by $48.50 \%$, FOC .by $58.40 \%$; Fraction - $E$ of the methanol extract reduced MABP by $60.60 \%$, HR by $58.60 \%$, FOC by $65.80 \%$; compared to atenolol which lowered MABP by $52.80 \%$, HR by $50.60 \%$, and FOC by $58.80 \%$; acetylcholine which reduced MABP by $30.50 \%$ HR by $33.60 \%$, and FOC by $10.50 \%$ in the presence and absence of norepinephrine. Preliminary phytochemical analysis by HPLC indicate the presence of flavonoids, terpenoids, saponins, tannins, cardiac glycoside, alkaloids, columbamine, berberine and naringin.

Conclusion: The results show that Coscinium fenestratum extract lowers MABP, HR and FOC in rats. These effects may be due to the bioactive components present in the extract.
\end{abstract}

Keywords: Coscinium fenestratum, Hypertension, Norepinephrine, Acetylcholine, Atenolol

\begin{abstract}
This is an Open Access article that uses a funding model which does not charge readers or their institutions for access and distributed under the terms of the Creative Commons Attribution License (http://creativecommons.org/licenses/by/4.0) and the Budapest Open Access Initiative (http://www.budapestopenaccessinitiative.org/read), which permit unrestricted use, distribution, and reproduction in any medium, provided the original work is properly credited.

Tropical Journal of Pharmaceutical Research is indexed by Science Citation Index (SciSearch), Scopus, International Pharmaceutical Abstract, Chemical Abstracts, Embase, Index Copernicus, EBSCO, African Index Medicus, JournalSeek, Journal Citation Reports/Science Edition, Directory of Open Access Journals (DOAJ), African Journal Online, Bioline International, Open-J-Gate and Pharmacy Abstracts
\end{abstract}

\section{INTRODUCTION}

According to the world health organization (WHO), hypertension is defined as a blood pressure level above 140/90 $\mathrm{mmHg}$ [1]. Hypertension currently affects nearly 78 million adults in the United States and has been termed a "silent killer" because it sometimes does not 
show symptoms and is a major modifiable factor contributing to cardiovascular and stroke morbidity and mortality [2].

Mortality from cardiovascular disease has risen rapidly over a fairly short period due to changes in environmental risk factors, such as diet and physical activity [3]. Data released by the National Health and Nutrition Evaluation Survey (NHANES) in $2007-2010$ reported that $81.5 \%$ of individuals with hypertension are not aware they have it. The data also reveal that $74.9 \%$ of patients who are aware of their hypertension receive treatment, and only $52.5 \%$ of those patients are under control, with significant variation across different patient subgroups [4].

The combined direct and indirect costs of hypertension were estimated at $\$ 69.9$ billion in 2008, considering the number of patients and their families impacted as well as the healthcare dollars spent on treatment and blood pressurerelated complications [5]. Heidereich et al [5] claim that hypertension cases increased by 46 $\%$, contributing to an increase in stroke cases and resulting in approximately $15 \%$ of the 2.4 million total deaths in the United States in 2009.

There is a global need to effectively track and improve health care interventions for high blood pressure, as the number of people with uncontrolled hypertension has increased to approximately 1 billion worldwide over the past three decades [6]. Plant extracts and herbal source may provide hope for the elusive goal of controlling hypertension or high blood pressure. Coscinium fenestratum (CF) Colebr is a commonly used medicinal plant in the family of Menispermaceae, and it is widely distributed in South-East Asia and the Indochina region [7].

The stem of this plant has been claimed to possess hypoglycemic, hypotensive, laxative, anti-inflammatory, anti-diarrhoea, anti-jaundice, anti-ulcer, anti-malarial and anti-diabetic activity [7]. A few scientific researchers have shown that it has anti-diabetic [8], anti-ulcer and antioxidant effects [9-11]. Bereberine, a major constituent of Coscinium fenestratum extract, possesses an anti-proliferative effect against nasopharyngeal carcinoma cell lines [12]. We also reported the presence of bereberine and palmatine $[8,13,14]$ in Coscinium fenestratum extract.

\section{EXPERIMENTAL}

\section{Chemicals}

The following chemicals were used for this research: methanol (Me), dichloromethane
(DCM), butanol $(\mathrm{BuOH})$, ethyl acetate $(\mathrm{EA})$, and hexane (Hex) (Mallinckrodt Chemicals, USA); dimethylsulphoxide (DMSO) (Fisher Scientific UK); acetone (Merck, Malaysia); and acetylcholine, athenol, and norepinephrine (Sigma USA).

\section{Plant material}

Coscinium fenestratum (CF) stem was identified and given to us by Dr. Shamsul Khamis, a taxonomist at the Laboratory of Natural Products, Institute of Bioscience, University Putra Malaysia (UPM). The plant was collected in the month of August 2014 in Perak Forest. Voucher specimen number 45 was assigned to the sample, and it was stored in the herbarium of the Laboratory of Natural Products, Institute of Bioscience, University Putra Malaysia (UPM). The stem was ground using a grinder and was macerated in methanol for $48 \mathrm{~h}$ at room temperature.

The mixture (methanol plus powdered stem) was filtered using Whatman filter paper, and the filtrate that contained the methanol crude extract was dried by evaporation using a rotary evaporator at a temperature of $45{ }^{\circ} \mathrm{C}$ with a rotation speed of $30-40 \mathrm{rpm}$. A dark brownish yellow residue was formed at the bottom of the flask and was collected as the crude methanol extract. Dichloromethane (DCM), ethyl acetate $(\mathrm{EA})$ and butanol $(\mathrm{BuOH})$ extracts were obtained by mixing the crude methanol extracts with water and then fractionating with the appropriate organic solvent in a $1000 \mathrm{ml}$ separating funnel. The resulting filtrate was dried with a rotary evaporator to obtain the extracts. The methanol extract was separated into fractions A - E using column chromatography with a silica gel and a mobile phase of $70 \%$ hexane and $30 \%$ EA.

\section{Animal models}

Sprague-Dawley rats (20) of both sexes with body weight $250-300 \mathrm{~g}$ and large live bull frogs (20) of either sex were obtained from the Institute of Medical Research (IMR) Kuala Lumpur Malaysia. The animals were housed in steel cages at a room temperature of $26 \pm 2{ }^{\circ} \mathrm{C}$ for at least 2 weeks to acclimatize before the beginning of the experiment. The animal studies were approved by the Animal Ethics Committee of UCSI (no. UCSI - FAS - MY 039 - 16). The animal work was in compliance with the guidelines of Animals (Scientific Procedures) Act 1986 Amendment Regulations with regard to Directive 2010/63/EU of the European Parliament and of the Council on the protection of animals used for scientific purposes published 3 August 2012 [15]. 
The frogs were placed on their backs on a rubber tray with the frontal portion facing upwards and the legs pinned to the rubber tray. Scissors and forceps were used to dissect the frog to expose the heart. A heart clip was used to clip the apex of the heart, and a thread was tied from the heart clip to a force transducer placed on the retort stand. The force transducer was then connected to BIOPAC Lab Pro Software (BIOPAC Systems, Inc., of Goleta, California) installed on a workstation. Nembutal $60 \mathrm{mg} / \mathrm{kg}$ (pentobarbital sodium) was injected intra - peritoneally (i. p.) into the rat. Once the rat was sedated, an incision was made, the trachea was cannulated, and a catheter tube was inserted into the open trachea to allow for spontaneous respiration $[16,17]$. The jugular vein and carotid veins were cannulated, and a catheter tube was inserted and connected to a pressure transducer connected to the BIOPAC Lab Pro Software system [18]. The extracts were dissolved in Tween 20 and glycerol $(1 \mathrm{~g} / \mathrm{ml})$ and serially diluted to $1 \mu \mathrm{g} / \mathrm{ml}-10 \mu \mathrm{g} / \mathrm{ml}$ with Ringer's solution (frog) or heparinized saline (rat). As a previous preliminary screening experiment showed that $5 \mu \mathrm{g} / \mathrm{ml}$ of the extracts yielded the best effect (data not shown), we used $5 \mu \mathrm{g} / \mathrm{ml}$ for all the experiments.

The extracts were applied onto the surface of the frog's heart or injected into the jugular vein of the rat. Five trial runs were performed to obtain an accurate average reading. The FOC of the frog was measured every $10 \mathrm{~s}$ for a total of $60 \mathrm{~s}$ using BIOPAC Lab Pro Software. Similarly, the MABP and $H R$ were measured every 30 seconds for a total 60 seconds. Heparinized saline solution (0.5 $\mathrm{mL}$ ) was used to push the extract into the jugular vein of the rat after a $60 \mathrm{~s}$ interval. Ringer's solution was used to wash the extract away from the frog's heart after each concentration was administered, as well as to keep the frog's heart moist and alive. Acetylcholine $(5 \mathrm{ug} / \mathrm{ml})$ was used as a positive control.

In another experiment, the extract was used to inhibit the contractions caused by norepinephrine: $5 \mu \mathrm{g} / \mathrm{ml}$ of each extract was applied onto the surface of the frog's heart or injected into the jugular vein of the rat, followed by $2 \mu \mathrm{g} / \mathrm{ml}$ norepinephrine. Five trials were performed to obtain an accurate average reading. The FOC of the frog was measured every $10 \mathrm{~s}$ for a total of $60 \mathrm{~s}$ using BIOPAC Lab Pro Software. Similarly, the MABP and HR of the rat were measured every 30 seconds for a total 60 seconds. Heparinized saline solution $(0.5 \mathrm{ml})$ was used to push the extract into the jugular vein of the rat after 60 seconds. Ringer's solution was used to wash the extract away from the frog's heart after each concentration was administered as well as to keep the frog's heart moist and alive. Atenolol $(5 \mu \mathrm{g} / \mathrm{ml})$ and acetylcholine (5 $\mu \mathrm{g} / \mathrm{ml}$ ) was used as control, both drugs were administered to the animal through the cannulated catheter tube that was inserted in jugular vein of the animal.

\section{HPLC analysis}

CF extract was dissolved in $10 \% \mathrm{MeOH}$ and 90 $\%$ ultra - pure $\mathrm{H}_{2} \mathrm{O}$ with the addition of $0.1 \%$ orthophosphoric acid. The optimal HPLC conditions are as follows: $20 \mu \mathrm{L}$ injection volume, $1 \mathrm{ml} / \mathrm{min}$ flow rate, $20 \mathrm{~min}$ run time, a column temperature of $30^{\circ} \mathrm{C}$, and a UV-DAD wavelength of $226 \mathrm{~nm}$. HPLC analysis was performed using the ZORBAX Eclipse XDB - C18 column, $4.6 \mathrm{~mm}$ $x 150 \mathrm{~mm}, 5$ micron particle size. The extract was injected at 100 ppm in $95 \%$ ultra-pure $\mathrm{H}_{2} \mathrm{O}$ + $0.1 \%$ orthophosphoric acid, and $5 \% \mathrm{MeOH}+$ $0.1 \%$ orthophosphoric acid was used as the mobile phase.

\section{Preliminary phytochemical screening}

A preliminary phytochemical analysis of Coscinium fenestratum was performed to assess the presence of different phytochemicals [19].

\section{Test for carbohydrates}

A few drops of concentrated sulphuric acid were added to a $1 \mathrm{ml}: 2 \mathrm{ml}$ mixture of Molisch's reagent and plant extract. If carbohydrates were present, the mixture would change colour to purple or reddish.

\section{Test for tannins}

To identify tannins, plant extract and $5 \%$ ferric chloride were mixed at the ratio of $1: 2$. The presence of tannins would lead to the formation of a dark blue or greenish black colour.

\section{Test for saponins}

To identify saponins, $2 \mathrm{ml}$ plant extract was mixed with $2 \mathrm{ml}$ distilled water. The mixture was shaken for 15 minutes. The presence of saponins would lead to the formation of a $1 \mathrm{~cm}$ layer of foam.

\section{Test for flavonoids}

The presence of flavonoids was identified based on a yellow colour change when $1 \mathrm{ml}$ plant extract was mixed with $1 \mathrm{ml}$ of $2 \mathrm{M}$ sodium hydroxide. 


\section{Test for alkaloids}

To identify alkaloids, plant extract and concentrated hydrochloric acid were mixed at a ratio of $2: 2 \mathrm{ml}$ with a few drops of Mayer's reagent. The presence of alkaloids would cause the appearance of a green colour or a white precipitate.

\section{Test for quinines}

Quinines were identified based on the appearance of a red colour in a 1:1 mixture of plant extract and concentrated sulphuric acid.

\section{Test for glycosides}

To identify glycosides, plant extract was mixed with chloroform and a $10 \%$ ammonia solution at the ratio of $2: 3: 1$. The formation of a pink colour would indicate the presence of glycosides.

\section{Test for cardiac glycosides}

To identify cardiac glycosides, a few drops of 5 $\%$ ferric chloride were added to a mixture of 0.5 $\mathrm{ml}$ plant extract, $2 \mathrm{ml}$ of glacial acetic acid and 1 $\mathrm{ml}$ of concentrated sulphuric acid. The formation of a brown ring at the interface would indicate the presence of cardiac glycosides.

\section{Test for terpenoids}

To identify terpenoids, plant extract and chloroform were mixed in the ratio of $0.5: 2 \mathrm{ml}$ with a pinch of concentrated sulphuric acid. A red - brown colour at the interface indicates the presence of terpenoids.

\section{Test for triterpenoids}

To identify triterpenoids, plant extract and Libemann-Buchard reagent (acetic anhydride + concentrated sulphuric acid) were mixed in the ratio of 1.5: $1 \mathrm{ml}$. Formation of a blue green colour would indicate the presence of triterpenoids.

\section{Test for phenols}

To identify phenols, $1 \mathrm{ml}$ of the plant extract and $2 \mathrm{ml}$ of distilled water were mixed, and a few drops of $10 \%$ ferric chloride were added. The formation of a blue or green colour would indicate the presence of phenols.

\section{Test for coumarins}

Coumarins were identified based on the yellow colour of a 1:1 mixture of plant extract and $10 \%$ $\mathrm{NaOH}$.

\section{Test for proteins and amino acids (Ninhydrin test)}

To identify proteins and amino acids, a few drops of $0.2 \%$ ninhydrin was mixed with $2 \mathrm{ml}$ of plant extract and heated for 5 minutes. The formation of a blue colour would indicate the presence of proteins.

\section{Test steroids and phytosteroids}

For steroid and phytosteroid identification, plant extract and chloroform were mixed at a ratio of 1 $: 1 \mathrm{ml}$ with a few drops of concentrated sulphuric acid. The appearance of a brown ring would indicate the presence of steroids, and the appearance of a bluish-brown ring would indicate the presence of phytosteroids.

\section{Identification of phlobatannins}

To identify phlobatannins, a few drops of $2 \%$ $\mathrm{HCl}$ were added to $1 \mathrm{ml}$ of plant extract, and the appearance of a red colour precipitate indicated the presence of phlobatannins.

\section{Identification of anthraquinones}

To identify anthraquinones, a few drops of $10 \%$ ammonia solution were added to $1 \mathrm{ml}$ of plant extract. The appearance of a pink coloured precipitate would indicate the presence of anthraquinones.

\section{Determination of flavonoids}

The aluminum chloride colorimetric method was used to estimate the quantity of flavonoids [31]. Each plant extract was prepared at $1 \mathrm{mg} / \mathrm{ml}$, and $100 \mu \mathrm{l}$ or $250 \mu \mathrm{l}$ of each sample was placed in separate tubes and made up to $2 \mathrm{ml}$ with methanol, $0.1 \mathrm{ml}$ of $10 \%$ aluminium chloride and $0.1 \mathrm{ml}$ of $1 \mathrm{M}$ potassium acetate. Then, $2.8 \mathrm{ml}$ of methanol was added to this solution, and it was kept at room temperature for $30 \mathrm{~min}$. The absorbance of the reaction mixture was measured at $415 \mathrm{~nm}$. The flavonoid content was expressed in $\mathrm{mg} / \mathrm{g}$. Quercetin was used as a standard for this assay $(10 \mathrm{mg} / 100 \mathrm{ml})$. 
Test for fixed oil (Spot test)

A small quantity of powder/extract was pressed between the filter papers. Oil stains on the papers indicated the presence of fixed oils.

\section{Evaluation of quercetin}

Silica gel F 254 plates were used as the stationary phase, and ethylacetate:toluene $(3: 7)$ was used as the mobile phase. The formation of a grease spot would indicate the presence of fixed oils and fats. The limit of detection was $1000 \mu \mathrm{g} / \mathrm{ml}$. Quercetin $(1000 \mu \mathrm{g} / \mathrm{ml})$ was used as a standard. The scanning wavelength was $366 \mathrm{~nm}$, the migration distance was $90 \mathrm{~mm}$, and $272 \mathrm{~nm}$ was selected as the wavelength for overlaid spectra.

\section{Statistical analysis}

The data are expressed as the mean \pm standard deviation of the mean and were analysed by oneway analysis of variance (ANOVA) followed by Dunnett's test using Graph Pad Prism 6 software. Differences at $p<0.05$ were accepted as statistically significant in this study.

\section{RESULTS}

The extracts were able to reduce the MABP, HR, and FOC as measured using the BIOPAC Lab Pro Software. The data below shows the percentage reduction of the MABP, HR, and FOC induced by different extracts. The greatest effects were observed for the methanol extract $(\mathrm{M}-\mathrm{E})$ and Fraction $\mathrm{E}$ of the methanol extract. The methanol extract reduced the MABP by $36.94 \%$, the HR by $33.75 \%$, and the FOC by $54.69 \%$. Fraction $\mathrm{E}$ of the methanol extract reduced MABP by $45.44 \%$, HR by $40.65 \%$, and
FOC by $59.22 \%$. The details of these effects can be seen in (Table 1).

\section{Effect of extracts in the presence of norepinephrine}

The extracts inhibited the norepinephrineinduced increases in MABP, HR and FOC in animal models. This effect was measured using the BIOPAC Lab Pro Software. The data presented below show the percentage change caused by each extract in MABP, HR and FOC. The greatest effects were observed for the methanol and Fraction $\mathrm{E}$ of the methanol extract. The methanol extract (M-E) reduced the MABP by $45.60 \%$, HR by $48.50 \%$, and FOC by 58.40 $\%$, and Fraction-E of the methanol extract decreased MABP by $60.60 \%$, HR by $58.60 \%$, and FOC by $65.80 \%$. Atenolol reduced MABP by $52.80 \%$, HR by $50.60 \%$ and FOC by $58.80 \%$. The details of these effects are shown in (Table 2).

\section{Phytochemical screening}

The colorimetric biochemical tests showed that the following compounds were present in the extracts: flavonoid, alkaloid, saponin, terpenoid, quercetin, tannin, essential oil, phenol, catechin and coumarin in the extracts (Table 3 ).

\section{Chromatograms}

Chromatograms of CF extract were obtained at the UV wavelength of $226 \mathrm{~nm}$, and UV spectra of each peak were obtained. Three peaks were observed, with retention times of $9.887 \mathrm{~min}$, $10.222 \mathrm{~min}$ and $11.266 \mathrm{~min}$. Retention time and UV spectra were used to identify the bioactive compounds present in the CF extract. Based on

Table 1: The effect of the extracts on the mean arterial blood pressure (MABP), force of contraction (FOC) and heart rate $(\mathrm{HR})$ of anaesthetized normotensive rats

\begin{tabular}{|c|c|c|c|c|c|c|c|}
\hline \multirow[t]{2}{*}{1.1} & \multirow[t]{2}{*}{ EXTRACT } & & \multirow{2}{*}{$\begin{array}{c}\text { MABP } \\
\text { REDUCTION } \\
(\%)\end{array}$} & \multicolumn{2}{|c|}{$1.3 \quad H R$} & \multicolumn{2}{|c|}{1.5} \\
\hline & & & & 1.4 & $\begin{array}{c}\text { REDUCTION } \\
(\%)\end{array}$ & 1.6 & $\begin{array}{c}\text { REDUCTION } \\
(\%)\end{array}$ \\
\hline 1.7 & $\mathrm{M}-\mathrm{E}$ & 1.8 & $36.94 \pm 0.49$ & 1.9 & $33.75 \pm 0.34$ & 1.10 & $54.69 \pm 0.22$ \\
\hline 1.11 & DCM-E & 1.12 & $22.59 \pm 0.23$ & 1.13 & $22.59 \pm 0.23$ & 1.14 & $20.69 \pm 0.32$ \\
\hline 1.15 & BUTOH-E & 1.16 & $15.59 \pm 0.22$ & 1.17 & $11.38 \pm 0.25$ & 1.18 & $20.69 \pm 0.33$ \\
\hline 1.19 & $E A-E$ & 1.20 & $18.83 \pm 0.35$ & 1.21 & $18.81 \pm 0.40$ & 1.22 & $25.66 \pm 0.23$ \\
\hline 1.23 & $\mathrm{ACH}$ & 1.24 & $17.90 \pm 0.34$ & 1.25 & $17.90 \pm 0.36$ & 1.26 & $22.01 \pm 0.33$ \\
\hline 1.27 & FRACTION A & 1.28 & $28.70 \pm 0.38$ & 1.29 & $10.5 \pm 0.34$ & 1.30 & $28.63 \pm 0.34$ \\
\hline 1.31 & FRACTION B & 1.32 & $29.78 \pm 0.26$ & 1.33 & $8.12 \pm 0.23$ & 1.34 & $40.39 \pm 0.33$ \\
\hline 1.35 & FRACTION C & 1.36 & $10.92 \pm 0.28$ & 1.37 & $31.09 \pm 0.33$ & 1.38 & $52.55 \pm 0.44$ \\
\hline 1.39 & FRACTION D & 1.40 & $22.12 \pm 0.29$ & 1.41 & $39.35 \pm 0.32$ & 1.42 & $56.08 \pm 0.35$ \\
\hline 1.43 & FRACTION E & 1.44 & $45.44 \pm 0.32$ & 1.45 & $40.65 \pm 0.28$ & 1.46 & $59.22 \pm 0.36$ \\
\hline
\end{tabular}


Table 2: The effects of the extracts in the presence of norepinephrine on the mean arterial blood pressure (MABP), force of contraction (FOC), and heart rate $(\mathrm{HR})$ of pentobarbital-anaesthetized normotensive rats

\begin{tabular}{lccc}
\hline $\begin{array}{l}\text { Norepinephrine } \\
\text { + extract }\end{array}$ & $\begin{array}{c}\text { MABP } \\
\text { reduction (\%) }\end{array}$ & $\begin{array}{c}1.47 \quad \text { HR } \\
\text { reduction (\%) }\end{array}$ & $\begin{array}{c}1.48 \text { FOC } \\
\text { reduction (\%) }\end{array}$ \\
\hline M-E & $45.60 \pm 0.33$ & $48.50 \pm 0.40$ & $58.40 \pm 0.36$ \\
DCM-E & $30.80 \pm 0.23$ & $32.60 \pm 0.39$ & $28.60 \pm 0.38$ \\
BUtOH-E & $25.60 \pm 0.34$ & $22.60 \pm 0.35$ & $25.80 \pm 0.37$ \\
EA-E & $25.60 \pm 0.26$ & $27.50 \pm 0.36$ & $30.60 \pm 0.33$ \\
Ach & $30.50 \pm 0.33$ & $33.60 \pm 0.35$ & $10.50 \pm 0.34$ \\
Fraction A & $37.50 \pm 0.38$ & $38.50 \pm 0.37$ & $35.30 \pm 0.32$ \\
Fraction B & $35.60 \pm 0.34$ & $36.50 \pm 0.32$ & $48.30 \pm 0.27$ \\
Fraction C & $17.20 \pm 0.33$ & $35.60 \pm 0.31$ & $56.60 \pm 0.44$ \\
Fraction D & $50.80 \pm 0.38$ & $45.40 \pm 0.22$ & $60.05 \pm 0.33$ \\
Fraction E & $60.60 \pm 0.36$ & $58.60 \pm 0.30$ & $65.80 \pm 0.32$ \\
Atenolol & $52.80 \pm 0.23$ & $50.60 \pm 0.37$ & $58.80 \pm 0.22$ \\
\hline ues were expressed as mean $\pm \mathrm{SEM}(\mathrm{N}=6)$. Significant at ${ }^{*} p<0.05,{ }^{* *} p<0.01,{ }^{* * * *} p<0.0001$
\end{tabular}

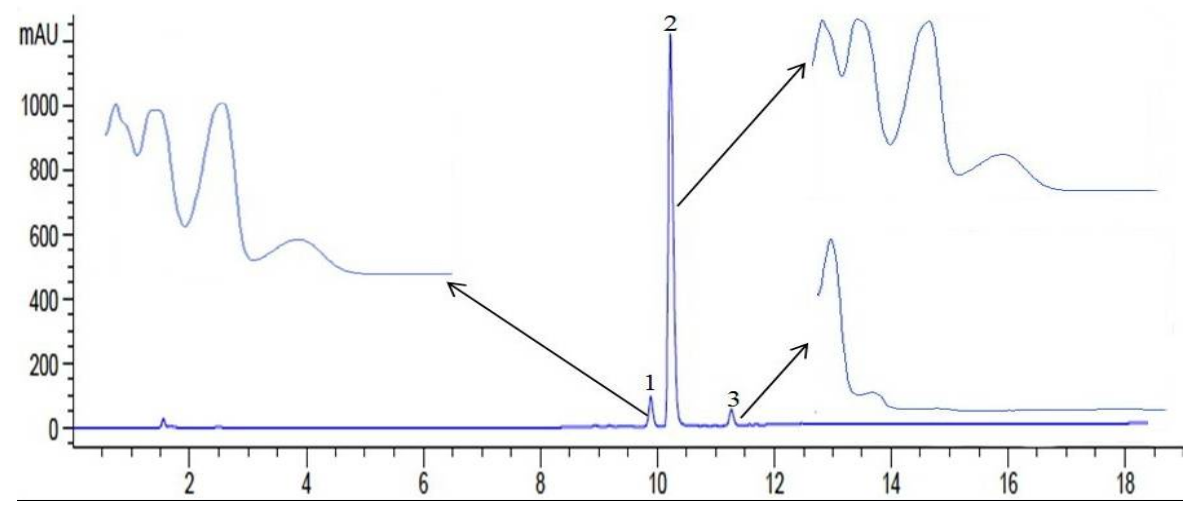

Figure 1: Chromatogram of CF extract obtained at $226 \mathrm{~nm}$, with the UV spectra of the peaks displayed in the inset. Three peaks were observed. The retention times of these peaks were 9.887, 10.222 and 11.266 min, respectively

Table 3: Phytochemical profile of the extracts

\begin{tabular}{lc}
\hline Phytoconstituent & $\begin{array}{c}\text { Present (+) } \\
\text { or absent (-) }\end{array}$ \\
\hline Flavonoid & + \\
Alkaloid & + \\
Saponin & + \\
Terpenoid & + \\
Quercetin & + \\
Tannin & + \\
Essential oil & + \\
Phenol & + \\
Sugar & - \\
Xanthoprotein & - \\
Steroid & - \\
Quinone & - \\
Anthraquinone & - \\
Catechin & + \\
Coumarin & + \\
\hline
\end{tabular}

the search results, peak 1 was suspected to be columbamine, jatrorrhizine, and palmatine, peak 2 was suspected to be berberine, and peak 3 was consistent with naringin (Figure 1).

\section{DISCUSSION}

Hypertension is a serious problem facing society, and most drugs on the market are not very effective in treating hypertension. Considering reports in the literature $[5,6,19]$, there is clearly an urgent need to declare an emergency in the search for alternative approaches to the treatment of hypertension. Coscinium fenestratum extracts were found to exhibit strong potential as drug candidates for the treatment of hypertension. The results showed that methanol extract and fraction $E$ of the methanol extract were able to significantly reduce MABP and HR in entobarbital-anaesthetized normotensive rats and FOC in perfused frog hearts, and the effect of these extracts was greater than that of acetylcholine.

These results suggest that the extract may have decreased atrioventricular conduction and decreased the force of atrial contractions. The efflux of potassium from the cell causes an increase in polarization and cellular hyperpolarization, decreasing atrial contraction. This occurs when the potassium channels linked to the $\mathrm{G}$ proteins open. The decrease in the force of contraction which is caused by a decrease in $\mathrm{Ca}^{2+}$ entry into the cell is probably due to the inhibition of adenylyl cyclase [20]. The extract 
may have induced arteriolar vasodilation by activation of the endothelium by a vasodilator compound, initially called EDRF (Endothelium Derived Relaxation Factor) and later identified as nitric oxide [20].

The extracts acted as beta blockers by antagonizing the effect of norepinephrine in the animal models. Norepinephrine has been known to activate the beta 1 receptors in the heart by acting as a positive ionotropic agent. This causes an increase in heart rate, force of contraction, and blood pressure [21]. The effect of the extract was seen to be more effective than that of the commercial drug atenolol. The pathogenesis of diseases such as atherosclerosis, diabetes, ischaemic heart disease, heart failure and hypertension has been linked to inflammation and reactive oxygen species. Reduction or prevention of oxidative stress-induced damage will help in the management of hypertension [22]. The phytochemical screening revealed the presence of key bioactive compounds such as flavonoid, alkaloid, saponin, terpenoid, quercetin, tannin, essential oil, phenol, catechin and coumarin. These phytochemicals have previously been reported to exhibit strong antioxidant effects, with the ability to reduce high blood pressure, reduce insulin resistance, improve endothelium-dependent vasodilation in hypertensive individuals, and exert significant effects on LDL and HDL [23].

Flavonoids have been reported to modulate blood pressure by restoring endothelial function, by affecting nitric oxide levels or through other pathways. Quercetin, flavonoids and related bioflavonoids have been reported to exhibit vasodilator effects on isolated aortae stimulated with noradrenaline, $\mathrm{KCl}$ or phorbol esters, and these effects are independent of the presence of endothelium. The anti-hypertensive effect of quercetin and flavonoid observed in that study was suspected to occur through stimulation of vasodilators [24]. Tannins have been reported to possess antihypertensive effects and to reduce plate aggression.

Rebecca et al and Seigo et al reported that increasing intake of polyphenol-rich foods in the form of fruits and vegetables, berries and dark chocolate causes a significant improvement in endothelium-dependent vasodilation, reduces LDL oxidative susceptibility and has a beneficial effect on the plasma HDL cholesterol concentration in hypertensive individuals. Saad et al showed that 1, 8 - cineole, a terpenoid oxide that is present in many essential oils, exhibited cardiovascular activity. Catechins that are present in green tea have been reported to reduce body fat and cardiovascular risks in humans [25].

Hiroshi et al reported the effects of the coumarin compound osthol on blood pressure and lipid metabolism in stroke-prone spontaneously hypertensive rats. Many reports have linked antihypertensive and antioxidant activity to the various phytochemicals present in the extract. Antioxidants are important compounds that are useful in limiting the effects of reactive oxygen species (ROS) and lipid peroxidation, which is one of the factors that aids cardiovascular problems. HPLC analysis has demonstrated the presence of columbamine, jatrorrhizine, palmatine, berberine and naringin.

\section{CONCLUSION}

Coscinium fenestratum plant extracts reduced the MABP and HR of pentobarbitalanaesthetized normotensive rats and FOC in perfused frog hearts in the presence and absence of norepinephrine. The effect of the extract may be due to the presence of bioactive compounds that have previously been reported to possess antihypertensive and antioxidant activity. Based on the results of this study, this extract can be considered a candidate for further development as an anti - hypertensive drug.

\section{DECLARATIONS}

\section{Acknowledgement}

The authors would like to acknowledge UCSI University for providing a research grant for this experiment and Shaanxi Provincial People's Hospital for supporting the analysis of the results and providing software.

\section{Conflict of interest}

No conflict of interest is associated with this work.

\section{Authors' contribution}

All authors contributed to data analysis, the proposal to perform electrophysiology experiments, plant material extraction, and drafting and critically revising the paper, and all authors agreed to be accountable for all aspects of the work.

\section{REFERENCES}

1. Lifton RP. Molecular genetics of human blood pressure variation, Science. 1996 May 3; 272(5262): 676-680.

Trop J Pharm Res, June 2018; 17(6): 1079 
2. Gavras H. Pathogenesis of hypertension: a review, J Med Sci 2009; 2(1): 25-28.

3. Yusuf S, Reddy S, Ounpuu S, Anand S. Global burden of cardiovascular diseases Part II : variations in cardiovascular disease by specific ethnic groups and geographic regions and prevention strategies. Circulation. 2001; 104 : 2855 - 2864.

4. Kearney PM, Whelton M, Kristi R, Muntner $P$, Whelton $P K$, Jiang $H$. Global burden of hypertension: analysis of worldwide data. Lancet. 2005; 365 : 217 - 223.

5. Heidenreich PA, Trogdon JG, Khavjou OA, Butler J, Dracup $K$, Ezekowitz $M D$, Finkelstein $E A$, Hong $Y$, Johnston SC, Khera $A$ et al. Forecasting the future of cardiovascular disease in the United States: a policy statement from the American Heart Association. Circulation. 2011; 123: 933 - 944.

6. Finucane MM, Stevens GA, Cowan MJ, Danaei G, Lin JK, Paciorek CJ, Singh GM, Gutierrez HR, Lu Y, Bahalim AN et al. Global Burden of Metabolic Risk Factors of Chronic Diseases Collaborating Group (Body Mass Index). Lancet. 2011; 377(9765): 557 - 567.

7. Wattanathorn J, Uabundit $N$, Itarat W, Mucimapura S, Laopatarakasem $P$, Sripanidkulchai $B$. Neurotoxicity of Cosinium fenestratum stem, a medicinal plant used in traditional medicine. Food Chem Toxicol. 2006; 44(8): 1327 - 1333.

8. Ekeuku SO, Okechukwu PN, Akuwoah GA, Teo SS, Froemming GRA. Plasma glucose lowering activity of Palmatine and its effect on liver, kidney and antioxidant enzymes parameters in STZ induced diabetic rat model. Current Bioactive Compound. 2015 (a); 11(4): 256 263.

9. Okechukwu NP, Akowuah GA. In vivo anti-ulcer and gastroprotective activities of dichloromethane extract of coscinium fenestratum stem Asian J Pharm Clin Res. 2014. 23; 45 - 55.

10. Venukumar MR, Latha MS. Antioxidant effect of Coscinium fenestratum in carbon tetrachloride treated rats. Indian Journal of Physiology and Pharmacology. 2002; 46 (2): 223 - 228.

11. Punitha IS, Rajendran K, Shirwaikar A, Shirwaikar A. Alcoholic stem extract of Coscinium fenestratum regulates carbohydrate metabolism and improves antioxidant status in streptozotocin-nicotinamide induced diabetic rats. Evid Based Complement Alternat Med. 2005: 2(3): 375 - 381.

12. Dakar M, Lin VY, Akowuah GA, Okechukwu PN, Chiam NC. Anti-proliferative activity of Coscinium fenestratum extract on the Major constituent, bereberine, against nasopharyngeal carcinoma cell lines. The Natural Product Journal. 2013; 3, 42 - 51.
13. Ekeuku SO, Okechukwu PN, Akuwoah GA, Teo SS, Froemming GRA. Antidiabetic Effect of Partially Purified Fraction $E$ from the Stem Extract of Coscinium fenestratum. Global Journal of Pharmacology 2015 (b); 9(4): 316 - 325

14. Akowuah GA, Okechukwu PN, Chiam NC. Evaluation of HPLC and spectrophometeric methods for analysis of bioactive constituent berberine in stem extract of Cosinium fenestratum. ACTA Chromatographica. 2014; 26, 2: 243 - 254

15. Fatehi M, Saleh TM, Fatehi-Hassanabad Z, Farrokhfail $K$, Jafarzadeh M, Davodi S. A pharmacological Study on Berberis vulgaris fruit extract. J Ethnopharmacol. 2005; 102, 46 - 52.

16. Animals (Scientific Procedures) Act 1986 Amendment Regulations with regard to Directive 2010/63/EU of the European Parliament and of the Council on the protection of animals used for scientific purposes Published 3 August 2012.

17. Wongcome T, Panthong A, Jesadanont S, Kanjanapothi $D$, Taesotikul T, Lertprasertsuke N. Hypotensive effect and Toxicology of extract from Cosicinium Fenestratum, J Ethnopharmacol. 2007; 111: 468 - 475.

18. Xie YW, Xu HX, Dong H, Fiscus RR, But PPH. Role of Nitric oxide in the vasorelaxant and hypotensive effects of extract and purified tannins from Geumja ponicum. $J$ Ethnopharmacol. 2007; 109: 128 - 133.

19. Sadasivam S, Manickam A. Biochemical Methods for Agricultural Sciences, New Age International $(P)$ Ltd., New Delhi, India, 1996; 1 - 97.

20. The NCD Alliance [Internet].Global NCD framework campaign. Geneva: NCD Alliance. Available from: http://www.ncdalliance.org/global-ncdframeworkcampaign 2012 [accessed 19 September 2016].

21. http://www.medicalnewstoday.com/articles/173068.php accessed on 9/11/2016.

22. Griendling KK, Alexander RW. Oxidative stress and cardiovascular disease. (PMID: 9396412) Circulation. 2007; 96(10): 3264 - 3265.

23. Davide G, Stefano N, Cristina L, Giuseppe C, Letizia V, Paolo $P$, Giovambattista $D$, Jeffrey BB, Claudio $F$. Cocoa Reduces Blood Pressure and Insulin Resistance and Improves Endothelium - Dependent Vasodilation in Hypertensives. Hypertension. 2005; 46: 398 - 405.

24. Duarte J, Vizcaíno FP, Utrilla P, Jiménez J, Tamargo J, Zarzuelo A. Vasodilatory effects of flavonoids in rat aortic smooth muscle. Structure-activity relationships. Gen Pharmacol. 1993: 24(4) : 857 - 862

25. Nagao T, Tadashi H, Ichiro T. A green tea extract high in catechins reduces body fat and cardiovascular risks in humans. Obesity. 2007; 15: 1473 - 1483. 